\title{
Tus historias me ayudan a crecer: relaciones entre biblioteca pública, lectura y primera infancia
}

Yicel Nayrobis Giraldo Giraldo

Bibliotecóloga. Magíster en Educación y Desarrollo Humano. Candidata a Doctora en Ciencias Sociales, Niñez y Juventud. Directora Maestría en Educación y Desarrollo Humano, convenio CINDE-Universidad de Manizales

Doris Liliana Henao Henao

Bibliotecóloga. Especialista en Comunicación Organizacional. Magíster en Educación $y$ Desarrollo Humano. Docente de la Universidad de Antioquia. Coordinadora del Centro de Información Periodística de El Colombiano

Sandra Inés Zuluaga Sánchez

Comunicadora social. Magíster en Educación y Desarrollo Humano. Líder asignación de recursos. Fundación Éxito

Margarita María Corrales Urrea

Trabajadora social. Magíster en Educación y Desarrollo Humano. Coordinadora General del Programa vecinos y amigos. Corporación Presencia Colombo Suiza

El artículo presenta los resultados de la investigación titulada "Tus historias me ayudan a crecer". Este trabajo tuvo como objetivo aproximarse a la comprensión de las transformaciones de los vínculos afectivos en familias con niños y niñas en primera infancia, que participan en el Programa PARAMÁ PARAPÁ de la Fundación Ratón de Biblioteca en el barrio Villa de Guadalupe de Medellín. Para el desarrollo de la investigación se optó por una metodología cualitativa, con una orientación hermenéutica, a partir de la cual se pudo concluir que los programas de promoción de lectura contribuyen al fortalecimiento de los vínculos afectivos, a la formación de prácticas de crianza favorecedoras del crecimiento de los niños y las niñas desde los primeros años de vida y a la transformación de la biblioteca pública en una institución 
social que contribuye a la potenciación del afecto entre los niños y las niñas y sus familias. Así pues, las estrategias de promoción de lectura son una apuesta metodológica valiosa para convocar en torno a iniciativas de fortalecimiento familiar, crecimiento y desarrollo de la infancia.

Palabras-claves: Lectura; Biblioteca pública; Vínculo afectivo; Primera infancia; Prácticas de crianza; Maternidad.

\section{Suas histórias me ajudam a crescer: relações entre biblioteca pública, a leitura e a primeira infância}

O artigo apresenta os resultados da pesquisa intitulada "Suas histórias me ajudam a crescer". Este estudo teve como objetivo abordar a compreensão das transformações do vínculo afetivo em famílias com crianças na primeira infância, participando do programa PARAMA PARAPA, da Fundação Ratón de Biblioteca do bairro Guadalupe de Medellín. Para o desenvolvimento da pesquisa, optamos por uma metodologia qualitativa, uma orientação hermenêutica, da qual se concluiu que os programas de promoção da leitura ajudam a fortalecer $o$ vínculo, a formação de práticas de criação que favoreceram o crescimento das crianças desde os primeiros anos de vida e a transformação da biblioteca pública em uma instituição social, que contribui para a potencialização do afeto entre crianças e suas famílias. Assim, as estratégias para promover a leitura é um compromisso metodológico valioso para convocar iniciativas destinadas a fortalecer as famílias, o crescimento e o desenvolvimento das crianças.

Palavras-chave: Leitura; Biblioteca pública; Vínculo afetivo; Primeira infância; Práticas da criação; Maternidade. 


\title{
Your stories help me grow:relationships between public library, reading and early childhood
}

\begin{abstract}
The article presents the results of the research titled "Your stories help me grow". This work aimed to approximate to the comprehension of the transformations of the affective ties in families with children in early childhood, participating in the program PARAMÁ PARAPÁ of the Fundación Ratón de Biblioteca in the Villa Guadalupe neighborhood in Medellin. The development of research opted for a qualitative methodology, with a hermeneutic orientation which could conclude that reading promotion programs contribute to the strengthening of the affective links, the formation of parenting practices which promote the growth of the children from the earliest years of life and the transformation of the public library in a social institution that contributes to the empowerment of the affection between boys and girls and their families. So that, promotion of reading strategies are thus a valuable methodological commitment to convene on initiatives of family strengthening, growth and development of children.
\end{abstract}

Keywords: Reading; Public library; Affective link; Early childhood; Parenting practices; Motherhood.

Recebido em 26.01.2013 Aceito em 06.03.2013

\section{Introducción}

No quiero sostener que la lectura y, sobre todo, una lectura mejor tiene como fin arreglar los problemas de la humanidad. [...] Lo que quiero decir es que el fin de la lectura es que el lector deje de leer y mire a quien tiene a su lado. [...] Creo que la lectura nos ayuda a entender en qué consiste vivir en un "mundo narrado" repleto de múltiples historias y de mitos (BÁRCENA, 2004).

El presente artículo se deriva de la investigación "Tus historias me ayudan a crecer" realizada por Doris Liliana Henao Henao, Margarita María Corrales Urrea y Sandra Inés Zuluaga Sánchez, como requisito parcial 
para obtener el título de Magíster en Educación y Desarrollo Humano, ofrecido por la Universidad de Manizales en convenio con la Fundación Centro Internacional de Educación y Desarrollo Humano - CINDE. Este trabajo tuvo como objetivo general aproximarse a la comprensión de las transformaciones de los vínculos afectivos en familias con niños y niñas en primera infancia, que participan en el Programa PARAMÁ PARAPÁ ${ }^{1}$ de la Fundación Ratón de Biblioteca en el barrio Villa de Guadalupe de Medellín.

De manera particular, la investigación reconoce la existencia de falta de acompañamiento de las familias, que viven en contextos vulnerables, para con los niños y niñas en la primera infancia y las deficiencias en las capacidades de los adultos significativos para comunicarse con ellos y crear ambientes estimulantes. Así mismo, se plantea la necesidad de reflexionar el lugar que puede llegar a ocupar la lectura, como práctica social, en el fortalecimiento del vínculo afectivo en la familia. En los últimos años, la biblioteca pública ha puesto en marcha iniciativas que están dirigidas básicamente a las familias y a los niños y niñas que se encuentran entre los 0 y 6 años, por lo que es importante pensar que están haciendo y que contribuciones pueden hacer al campo de trabajo con la primera infancia.

La investigación en mención se realizó en el barrio Villa de Guadalupe de Medellín, una zona de la ciudad afectada por diferentes problemáticas sociales como la violencia y el desplazamiento forzado. Particularmente, se contó con la participación de los asistentes al Programa PARAMÁ PARAPÁ de la Fundación Ratón de Biblioteca, institución que por más de 30 años viene desarrollando actividades de promoción de la lectura en esta comunidad.

Con el fin de facilitar el abordaje de la investigación, el artículo está estructurado de la siguiente forma: en primer lugar, ubica el problema de investigación, las preguntas orientadoras del estudio y la metodología implementada; en segundo lugar, da cuenta del contexto en el que se desarrolla el trabajo; en tercer lugar, desarrolla un referente conceptual básico; en cuarto lugar, expone los hallazgos obtenidos durante el trabajo; y, en quinto lugar, plantea las conclusiones y formula algunas cuestiones de interés para futuros trabajos de investigación en el campo.

Se espera que el/la lector/a encuentre en este material interesantes referencias para reflexionar las relaciones de la lectura con la primera infancia, la familia y el vínculo afectivo. Sin duda, los niños y las niñas requieren del despliegue de iniciativas para la creación de ambientes educativos estimulantes y potenciadores del afecto, de ahí el interés en fomentar trabajos de investigación que puedan contribuir a la cualificación de las intervenciones en este ámbito.

\footnotetext{
'En el Proyecto Educativo Institucional 2010-2015 de la Fundación, el Taller PARAMÁ PARAPÁ está planteado como una estrategia de acercamiento y de formación con los padres de familia "Sobre la sensibilización afectiva y la reflexión permanente hacia el buen trato que deben tener con niños y las niñas, esto lo realizaremos por medio de acercamientos hacia la lectura y escritura de nanas, canciones de cuna, canciones infantiles, juegos de lenguaje, retahílas, trabalenguas, relatos, cuentos y libros de imágenes (libros álbum), libros ilustrados, esto nos posibilitará que entre todos formemos seres afectuosos, comprometidos con sus vidas y con un alto sentido social y humano (FUNDACIÓN RATÓN DE BIBLIOTECA, 2009, p. 42).
} 


\section{Generalidades de la investigación}

\subsection{Planteamiento del problema y preguntas de investigación}

Las inquietudes sobre la primera infancia y el vínculo afectivo surgen frente a la ausencia de trabajos de investigación que indaguen por las incidencias que pueden tener las acciones de promoción de la lectura y formación de lectores en edad temprana, muy especialmente, en el fortalecimiento del vínculo afectivo en familias con niños y niñas en primera infancia.

A partir del rastreo bibliográfico sobre el desarrollo de investigaciones y de programas en torno a la lectura y a la primera infancia, tanto en el país, como en el exterior, se ha podido encontrar que hay un significativo número de programas de promoción de lectura dirigidos a las familias con niños/as pequeños/as que buscan formar lectores/as e incidir en su desarrollo cognitivo, en los procesos de adquisición del lenguaje $y$ en el desarrollo de habilidades lógicomatemáticas.

Estos estudios de promoción de lectura se han preocupado principalmente por dilucidar los aspectos o elementos del proceso lector en el aprestamiento para la escuela, sin centrarse en temas como la incidencia que genera en sus comunidades y en el desarrollo social y afectivo de los niños y niñas y sus familias; de esta manera se evidenció una ausencia de trabajos que se pregunten explícitamente por la transformación de los vínculos afectivos en las familias con niños y niñas en primera infancia que asisten a este tipo de programas.

A lo anterior, se suman voces de entidades nacionales e internacionales que se preocupan por mejorar las condiciones de vida de los niños y de las niñas. Puntualmente, nos referimos a las palabras del presidente del BID, Luis Alberto Moreno (2009), acerca de la aguda situación por la que pasan nuestros niños y niñas frente a la carencia del relato y de la narración en sus vidas: "Un tercio de nuestros estudiantes de tercer grado no entienden oraciones que empiezan con: había una vez". También se encontró que en los procesos de seguimiento y evaluación que realiza la Fundación Éxito a los programas de nutrición cofinanciados a organizaciones sociales que imparten familias gestante, una madre lactando preguntó: ¿De qué le hablo a mi hijo?, y entre las directivas de las organizaciones de educación inicial se expresa permanentemente que los niños y las niñas tienen un bajo desarrollo del lenguaje porque no hay quién les hable en su hogar (FUNDACIÓN ÉXITO, 2009).

Esta información presume falta de acompañamiento de los niños y niñas por parte de sus familias y deficiencias en las capacidades de padres, madres y adultos significativos para comunicarse entre sí y crearles ambientes estimulantes para su crecimiento, situación que trae consigo consecuencias en el corto y largo plazo: 
Las familias son, de hecho, mucho más importantes a la hora de explicar los resultados escolares, que los insumos brindados por la escuela [...]. Por lo tanto un niño que ingresa a la escuela, que viene de una familia que no le ha leído, que no lo ha estimulado, ni desafiado de una manera efectiva, ese niño tiene una muy pobre perspectiva de futuro [...]. Las escuelas tienen que trabajar con lo que las familias y las comunidades les provean (HECKMAN, 2001, p. 7).

Esta serie de inquietudes ratifican la pertinencia de la investigación por el planteamiento del compromiso académico que se asume al comprender las condiciones sociales, educativas, culturales, políticas y económicas que están favoreciendo $o$ no el crecimiento y desarrollo emocional, físico y cognitivo de los niños y de las niñas. No obstante, este proyecto, hace especial énfasis en la dimensión emocional y afectiva de los niños y de las niñas en la primera infancia.

La revisión de los trabajos de investigación, así como el análisis del contexto y de las intervenciones de otras entidades y organizaciones sociales a nivel local y nacional, permitieron la formulación de la siguiente pregunta de investigación:

¿De qué manera y mediante qué procesos se transforman los vínculos afectivos en familias, con niños y niñas en primera infancia, que participan en el Programa PARAMÁ PARAPÁ de la Fundación Ratón de Biblioteca?

Esta pregunta se complementó con inquietudes como:

a) ¿Cuál es el papel de la biblioteca pública, como institución social formadora de lectores/as, en las prácticas de crianza de las familias con niños y niñas en primera infancia?

b) ¿Cómo procura la biblioteca pública un espacio para las familias con niños y niñas en primera infancia?

c) ¿Cómo y qué tipo de relaciones se forman (o transforman) por medio de la interacción de la biblioteca pública en las familias con niños y niñas en primera infancia?

En este sentido, esta investigación tuvo como objetivo general aproximarse a la comprensión de las transformaciones de los vínculos afectivos en familias con niños y niñas en primera infancia, que participan en el Programa PARAMÁ PARAPÁ de la Fundación Ratón de Biblioteca en el barrio Villa de Guadalupe de Medellín.

De modo concreto, se plantearon como objetivos específicos analizar las diferentes manifestaciones de afecto de los niños y niñas con los padres, que asisten al Programa PARAMÁ PARAPÁ; indagar por las relaciones vinculares que se establecen entre los niños y las niñas en primera infancia con los adultos que asisten al Programa PARAMÁ 
PARAPÁ; e identificar el papel que cumple la Fundación Ratón de Biblioteca, como institución social, en la comunidad de Villa de Guadalupe.

\subsection{Memoria metodológica}

En la investigación se acudió al enfoque cualitativo, desde una perspectiva hermenéutica, que permitió acercarse a la comprensión de un tema particular en una situación como el taller de PARAMÁ PARAPÁ a partir de la lectura de las narraciones y de los relatos construidos con los/as participantes. Dentro de este enfoque, la narrativa adquirió un papel importante, pues por medio de la palabra se comprendió la transformación del vínculo afectivo entre las familias que participan del programa de lectura, interpretando y develando el sentido de las historias y de los relatos obtenidos a través de las diferentes técnicas de recolección de datos.

Metodológicamente se abordaron las posturas de Gadamer con respecto a la identificación del ser con el lenguaje, también desde la hermenéutica de Paul Ricoeur donde la identificación del sujeto fue más allá del sujeto de conocimiento, pues se tuvo en cuenta su experiencia. En paralelo se revisó la producción teórica con el propósito de alcanzar la aproximación a elementos que permitieron comprender la transformación del vínculo afectivo.

Para la construcción de los datos su usaron estrategias que permitieron la recolección, el registro y el análisis de la información. Se recurrió al registro escrito y audiovisual como herramientas paralelas de la observación en cada sesión del taller PARAMÁ PARAPÁ. De manera concreta, se recurrió a: la observación participante de once sesiones del Programa; la entrevista semi-estructurada con 8 madres participantes del Programa PARAMÁ PARAPÁ; el taller tematizado ¿Qué es ser madre?; al análisis de los documentos institucionales de la Fundación Ratón de Biblioteca que tienen que ver con el Programa; a reuniones con expertos; y a la revisión de las producciones de los asistentes como ejercicios del taller.

\section{Referentes conceptuales}

Para el desarrollo de la investigación, se perfilaron las siguientes categorías:

\subsection{Primera infancia}

Para comenzar, es preciso comprender que la primera infancia es la etapa de la vida que va desde la gestación hasta los seis años, y es en la que se presenta el más rápido crecimiento y cambio de todo el ciclo vital, en términos de maduración del cuerpo y sistema nervioso, movilidad, capacidad de comunicación y aptitudes intelectuales. Se crean vínculos emocionales con los adultos significativos, sean sus padres o cuidadores, pues de ellos necesitan cuidado, atención, orientación y protección de 
acuerdo con sus características individuales. Se empiezan a establecer las bases para relacionarse con otros niños y con los adultos. Estas situaciones permiten aprender temas como la capacidad de interactuar con otros, establecer responsabilidades, negociar y resolver conflictos.

Igualmente es el periodo en que se captan las dimensiones físicas, sociales y culturales del mundo, se crean las bases para la salud física y mental, la seguridad emocional, la identidad cultural y personal y el desarrollo de las aptitudes. Hay evidencias que demuestran que experiencias tempranas sensoriales y emocionales tienen que ver con alteraciones de los circuitos del estrés: "los patrones de respuesta positivos 0 negativos pueden marcar diferencias significativas en el cociente intelectual de un niño, es decir que un bebe que reciba experiencias no estimulantes lleva una alta probabilidad de tener un coeficiente intelectual menor y desarrollar pobres habilidades, conductas antisociales, además de problemas físicos y mentales" (MUSTARD, 2003, p. 85).

Los niños y las niñas que asisten al taller son menores de tres años, la mayoría está en su primer año, un periodo en el cual conectan los sentidos con su cerebro, es decir necesitan relacionar la escucha y la motricidad para aprender posteriormente a hablar. Tienen un interés innato en explorar el mundo, pero necesitan que en su entorno se aprendan a leer sus mensajes para que se genere una cadena de respuestas entre madre e hijo que permita pasar del balbuceo, a la palabra y luego apropiarse de la lengua.

El afecto que se le expresa a un ser humano en sus primeros años de vida, se convierte en la confianza que le permite crecer, hacer amigos, aprender a atender a otros, negociar, y desarrollar la disciplina para construir una historia original y propia. El vínculo que desarrolla la madre desde la gestación potencia las capacidades que tendrá el bebe para leer las señales y para motivarse a iniciar su camino de crecimiento y desarrollo. Los niños y niñas acompañados de adultos hábiles para estimularlos en la medida de sus intereses y con capacidad para expresarles el afecto, lograrán expresar sus propias emociones y encontrar su capacidad de comunicación.

Es por ello que las múltiples posibilidades de expresión que ofrece el taller PARAMÁ PARAPÁ potencian las capacidades comunicativas de los/as participantes.

Los ambientes lingüísticamente enriquecedores, en los cuales los padres leen, responden y conversan incluso con los niños más pequeños promueven el desarrollo intelectual. Las destrezas cognitivas y lingüísticas pueden proteger contra la incidencia de problemas de conducta y de carácter emotivo, ya que los niños que no logran manifestar sus necesidades verbales frecuentemente fracasan en la escuela y en muchas otras circunstancias de la vida, en parte porque no pueden expresar sus sentimientos y explicar claramente lo que desean (OATES, 2007, p. 18). 


\subsection{La lectura}

En la primera infancia, leer no es una actividad aislada ni puramente intelectual sino que se relaciona con oír, mirar, oler, tocar, probar y moverse. Aceptar que los bebés comienzan "leyendo" con los oídos, con el tacto y con todo el cuerpo, implica replantear la idea de que en las bibliotecas de la primera infancia solo haya libros (REYES, 2003, p. 27)

Así, la lectura es más que un proceso de decodificar signos para darle un sentido contextual a una palabra o a una agrupación de palabras. La lectura, se entiende "como un proceso cognitivo, semiológico, cultural, social e histórico de carácter complejo e interactivo entre el mensaje expuesto en el texto (que no solo es el escrito) y el conocimiento, las expectativas y los propósitos del lector, en contextos sociales, culturales, políticos e históricos determinados" (ÁLVAREZ ZAPATA, 2008, p. 16). Es decir, la lectura involucra la interacción del mensaje, la experiencia del lector y el contexto particular, de ahí que sea un proceso complejo a partir del cual el lector construye realidades y sentidos sobre lo leído conjugado con rasgos de lo vivido, de lo tejido por otros que empieza a hacer parte del tejido narrativo de nuestra propia historia.

Para esta investigación emerge la idea de que con la lectura, la narración y el juego devienen situaciones que permiten la transformación del vínculo afectivo entre los niños y las niñas y los adultos significativos (o posibles cuidadores), pues las expresiones del afecto suceden por otros canales y vías, recurriendo a otros lenguajes. El amor se expresa de formas menos visibles a los ojos de los demás. Mediante la lectura se puede estrechar el contacto físico y visual entre dos seres (por ejemplo, el de la madre hacia su hijo). En la lectura nos reafirmamos como seres de necesidad, pero de aquella necesidad que habla del afecto, de sentir la calidez de las palabras y del regocijo de los brazos.

Como bien se ha dicho, lo que acontece en el encuentro suscitado por la lectura entre los niños y las niñas con sus padres o madres (cuidadores), hace parte del proceso de socialización primaria que no sólo brinda elementos para la interacción social como miembro de una comunidad, sino que también sentará las bases para la formación de su propia identidad mediante el reconocimiento favorable que los demás le otorgan en el devenir de su vida. Este reconocimiento le permite sentirse capaz requiriendo, a su vez, valoración y estima por los demás. Con esa certeza, del volverse capaz y ser reconocido (RICOEUR, 2005), los seres humanos procuran hallar mejores condiciones para encontrar plenamente estimadas sus particularidades y sus aportes a la construcción de un proyecto de vida común.

Es así como la pregunta por lo qué pasa con los vínculos en una familia, sea cual sea su composición, en la que los adultos leen con los niños en sus seis primeros años de edad, puede comprenderse como 
aquello que, a través del contacto físico, visual y auditivo, les permite entrar en contacto con el lenguaje y con la narración. Pues como dicen Berger y Luckmann: "la sociedad, la identidad y la realidad se cristalizan subjetivamente en el mismo proceso de internalización. Esta cristalización se corresponde con la internalización del lenguaje [...] el lenguaje [...] se constituye, por cierto, el contenido más importante y el instrumento más importante de la socialización" (2003, p. 169).

Entendida entonces la lectura como una actividad que descentra al sujeto y lo pone siempre en relación con los otros, se puede definir como una práctica social; así, retomando a Álvarez Zapata (2002), esta permite a los individuos la construcción de su esfera íntima y de su esfera social, individuación y socialización respectivamente, junto a otras prácticas sociales; es a partir de esta postura que el individuo se permite ser con otro, se da la posibilidad de conocer, establecer y/o fortalecer una relación de apego, amor y vínculo, pues en las relaciones afectivas la reafirmación y aprobación que encuentran los seres humanos en los otros les permite ganar confianza en sí mismo.

\subsection{La biblioteca públic}

En esta investigación se asume a la biblioteca pública como "una institución social, viva y dinámica, de ahí que sea un espacio construido e intervenido por las personas, en tanto les permite entrelazar, afinar, y construir el tejido social de la comunidad en la que se inscribe" (JARAMILLO et al., 2005, p. 122). Así que el trabajo de la biblioteca pública impacta todos los espacios del individuo posibilitando encuentros, participación y acceso a todo el acervo cultural de una sociedad determinada.

Este planteamiento a la luz de lo planteado por la IFLA/Unesco en el Manifiesto sobre la Biblioteca pública (1994) donde se define que ésta es "un centro local de información que facilita a sus usuarios todas las clases de conocimiento e información", permite concluir que ambas definiciones están alineadas en la medida en que establecen que la biblioteca pública debe ser un espacio que posibilita el acceso a la información a todos por igual. Así mismo, se puede afirmar que la garantía en el acceso a la información se verá reflejada en mejores condiciones de vida para los integrantes de una comunidad.

Por su caracterización como institución social, la biblioteca pública se ha transformado sobre la marcha de importantes proyectos sociales, políticos, económicos y culturales de la ciudad desde 1870, fecha en que se creó la primera biblioteca pública en la ciudad, la Biblioteca del Estado Soberano de Antioquia, hasta el movimiento bibliotecario actual promovido por las últimas administraciones municipales y diferentes actores del sector académico y cultural. Lo anterior evidencia la presencia de la biblioteca pública en el desarrollo social, cultural y político de la ciudad y del departamento de Antioquia, pues ella ha participado activamente en los diferentes proyectos de construcción y reconfiguración 
de la ciudad, en la legitimación de proyectos políticos y en la construcción de ideas de país, estado y nación.

Es precisamente a partir de la participación social de la biblioteca pública en los diferentes escenarios, lo que le ha permitido proyectarse con más fuerza en los espacios de acción y decisión del orden municipal, departamental y nacional, recibiendo apoyos que respaldan su quehacer, desde la promulgación de políticas nacionales y municipales para su fortalecimiento institucional hasta el apoyo para la realización de acciones cotidianas en las comunidades. Allí se perfilan como lugares que promueven el encuentro ciudadano y que enriquecen la vida interior y la vida en común con otros.

\subsection{La maternidad}

Para el desarrollo de la investigación, la pregunta por la maternidad cobra especial importancia, pues es importante indagar sobre el significado que tiene el ejercicio de este rol para las mujeres. Así mismo, se postula, a modo de supuesto de sentido, que la maternidad es una de las opciones a las que recurren las mujeres, en contextos de vulneración y de pobreza, para demostrar su feminidad ante las otras mujeres, en especial ante las de su familia. Con ello buscan ser reconocidas y valoradas por los miembros de la sociedad.

Después de esta importante consideración, se define a la maternidad como:

Un acto cívico e inscrito como deber fundamental de las mujeres, y no es considerada como un deseo. La maternidad se ha configurado en un ideal, y como tal, generador de un común denominador para las mujeres, brinda una respuesta y se evade una búsqueda, puesto que se ofrece una respuesta totalizante y a ello se denomina "la identidad femenina", situación que coloca a la mujer en una posición alienante por medio de la cual se le encubren carencias en donde habría la posibilidad de que emergiera en los diferentes deseos de las mujeres (SUÁREZ SERRANO, 2006, p, 3).

En el contexto donde se desarrolla la investigación, la figura femenina, en mayor medida, es la encargada del cuidado de los menores; esta función se antepone a otras que las mujeres puedan o decidan ejercer, pues se considera que la maternidad es en un hecho cultural y no natural, pues su ejercicio está suscrito a unos referentes culturales específicos y a los roles que las mujeres pueden o no ejercer en el marco de estas condiciones sociales.

La maternidad, en muchos contextos, se concibe como una obligación que debe ser ejercida en el seno de un matrimonio y de una familia, si bien se pudiera plantear que la sociedad exige a toda mujer que sea madre, la maternidad debe darse bajo determinados cánones para ser considerada normal. "Toda maternidad que quede fuera de este patrón es condenada, excluida y rechazada y se convierte en la víctima de la misma 
estructura que la impulsó a ser lo que ahora le recrimina" (GENOLET et al., 2009, p. 15).

Si bien existen tensiones entre el ejercicio de la maternidad y otras formas de realización femenina - que tienen que ver con lo laboral y profesional-, es importante reivindicar el rol de la madre en el proceso de formación y desarrollo de los niños y de las niñas. Con ello, no se quiere eximir al padre de su responsabilidad, sin embargo, la relación madre e hijo entraña comprensiones infinitamente complejas frente a esta relación de afecto y de cuidado. No sólo el hijo necesita de la madre, a su vez, ella requiere de su hijo. Por tanto, existe reciprocidad en la experiencia de la necesidad y en el poder contar con el otro para satisfacerla. En este marco, la maternidad es entendida como "una función social que implica una serie de complejos procesos psíquicos que realizan las mujeres a fin de satisfacer las necesidades alimenticias, de estímulos y de afecto que necesita el infante humano para devenir en sujeto" (GENOLET et al., 2009, p. 20).

\section{Hallazgos}

\subsection{De la participación en PARAMÁ PARAPÁ y otras historias}

El programa de promoción de lectura PARAMÁ PARAPÁ está constituido por una serie de talleres que se realizan una vez a la semana, los miércoles a las 4:00 p.m. Son sesiones de una hora en las que hay música, libros, literatura, conversación y manualidades entre otros, para recibir y acoger a todos los que llegan. Aunque el espacio responde a unos procesos de planeación, el orden del día es flexible y móvil, siempre que se ajuste a los intereses de los participantes, sin perder su intención.

En muchas ocasiones, los/as asistentes del taller de las 3:00 p.m. se quedan en el de las 4:00 p.m. porque quieren seguir participando de las actividades, la acogida del Programa en la comunidad puede evidenciarse en las expectativas que plantean: "Llegamos a Ratón por una vecina que asiste al taller, ella me invitó, diciéndome que era un taller de estimulación para los bebes" (Participante 3 ).

En los talleres de PARAMÁ PARAPÁ, las familias tienen la oportunidad de compartir sus conocimientos e inquietudes sobre la crianza, la experiencia de la paternidad y maternidad, además de entrar en contacto con la literatura, el arte y la fantasía.

\subsection{Más allá de la lectura... estás tú y estoy yo... estamos nosotros}

En cada sesión semanal del taller PARAMÁ PARAPÁ, la lectura es parte fundamental; sin embargo, no es sólo desde el libro, es la lectura del mundo, del contexto, del propio cuerpo y del de los niños y las niñas; la lectura y el libro se convierten en la excusa para el encuentro, en una 
posibilidad para que cada una de los/as participantes (entre los asistentes hay tías, abuelas, papás, primas, hermanos, en su mayoría son mamás) construyan e imaginen otros mundos posibles: todo se convierte en una invitación a soñar, a gozar, y a verse distintos en el universo.

Llegué a Ratón por el otro niño, él tenía 4 años y lo invitaron a unos talleres, fui a ver y me pareció bueno, entonces el niño empezó a estar en la biblioteca, yo llegaba a ratos para ver qué hacían. Entonces cuando nació Samuel me dijeron que iban a hacer unos talleres de tips para el crecimiento de los niños, charlas para las mamás, entonces me fui a ver. Además en el embarazo me gustaba ir a la biblioteca, pues ahí me relajaba (Participante 5).

Se lee en el taller y en la casa, pues la lectura está ligada al juego, a la literatura, a la narración y, por supuesto, a los libros; de las ocho mamás que participaron permanentemente en los talleres, solo una de ellas manifestó que la lectura estaba únicamente en el taller, para las demás, es un acto que tiene presencia en todos sus espacios y va desde el disfrute del tiempo libre, el acompañamiento en las tareas escolares, hasta el cuento en la noche antes de dormir. Algunos testimonios así lo evidencian:

a)-A él le gusta la lectura porque cuando yo estaba en embarazo, o sea yo soy una persona que le gusta mucho leer, desde la universidad... Para el bebé, los libros son su vida (Participante 1).

b)-A las niñas les ha servido porque ellas son enamoradas de los libros y ellas aquí se despiertan mucho (Participante 8).

c)-Le leo los cuentos a los niños y para mí. Leer los cuentos de misterio, de los egipcios, de cosas que son y no son, me gusta mucho, pero decir que libros de superación, no, es que yo soy una niña chiquita, sino tienen dibujos no me gustan (Participante 2).

Leer, en este contexto, tiene que ver con encontrar otras maneras de ver el mundo para acceder a nuevas formas de relacionarnos con los otros mediante la conexión entre la identidad propia y las diversas formas de expresión de los demás. 


\subsection{De los libros y otros cuentos}

Los libros aparecen en PARAMÁ PARAPÁ de una manera discreta, si bien están presentes en todas las sesiones no son los únicos protagonistas, permanecen en el espacio esperando su aparición en alguno de los momentos del Taller. Siempre están allí porque el coordinador lee algo, porque están expuestos, porque se llevan para que las mamás los escojan y lean, para que los niños y niñas los toquen, muerdan, sientan sus texturas, vean las imágenes, para argumentar algún tema.

Otra forma en la que aparece el libro es, precisamente, en la "mochila viajera", término utilizado en Ratón de Biblioteca para definir un bolso con libros seleccionados para que las familias se los lleven a sus casas. En esas mochilas van cuentos, poesías, rimas, narraciones pero también algunos libros sobre origami, manualidades y los sueños, entre otros temas; esto con la intención de que realmente se lea en el hogar. La apuesta que se hace es porque las mochilas roten permanentemente y los libros lleguen a la mayor cantidad de familias posibles; de diez mochilas que tiene Fundación Ratón de Biblioteca, en promedio aparecen prestadas siete. Solo una de las mamás que participan en el taller dijo no conocer la mochila. A continuación algunos testimonios sobre el uso y rotación de la mochila:

a)-La mochila la llevo cada ocho o quince días, me las llevo y reparto los libros entre las dos mamás para que se los lean en la casa (Participante 8).

b)-Mil y mil gracias Fundación Ratón de Biblioteca por permitirnos descubrir cada vez más el mundo a través de la lectura, me siento muy afortunada y feliz por pertenecer a esta Fundación además porque confían en mí y me prestan los libros para llevarlos a la casa. Los quiero mucho (Participante 9).

Cada mochila se presta por ocho días y contiene entre seis y ocho libros, una especie de "diario" en el que el lector puede hacer recomendaciones, comentarios o mencionar algún aspecto que haya llamado la atención: "Que por favor cuide el contenido de la mochila para que otras personas puedan disfrutar de ella. Los libros son sabios, traen mucha información que nos puede servir de mucho" (Participante10).

\subsection{De las razones y otras motivaciones}

Los adultos participantes son, en su mayoría, madres que llegaron tras la expectativa de aprender sobre cómo mejorar la crianza de sus hijos

-Porque cuando la niña estaba en el preescolar me mandaron una nota y yo empecé a venir y me gustó, y de quedarme en 
la casa, más bien me arreglo y me vengo para acá, con la primera vez que vine me gusto, me distraigo, nos ponen a hablar de todo, muy bueno este taller (Participante 2).

-Yo llegue acá cuando el bebé tenía 3 o 4 meses, yo llegué porque una muchacha, por donde yo hacia la labor social, me dijo -mira, allá abajo en Ratón de Biblioteca están haciendo unos cursos para niños, de estimulación, para que lo lleves (Participante 1).

Durante el periodo de observación del Programa, las actividades del taller incluyeron las indicaciones de cómo se practica el masaje shantala, una práctica de la India que les permite a los bebés percibir su cuerpo, entrar en contacto con la piel de su madre o de quien lo practica, percibir su olor y sentir su presencia. El masaje es un contacto que se suma a la lectura, con él, los adultos realizan una serie de caricias en el pecho, el estómago, los brazos, las manos, las piernas, los pies y la espalda del bebé: "Le hablo, le pongo música, le hago masajes y me relajo con ella" (Participante 3).

\subsection{De las historias que se escriben a diario}

Otro proceso fundamental en la programación de PARAMÁ PARAPÁ es la invitación a las familias para que escriban el diario del bebé, construyan su biografía. Esta actividad es bastante innovadora en la vida de los adultos asistentes, pues son personas que no tienen en su rutina la escritura; sin embargo cada madre se ha puesto en la tarea de poner en su propia voz, la del niño o la niña, la historia de cómo se enamoró del padre, cómo llegó la noticia de su gestación, cómo pasaron los nueve meses de vida en su cuerpo, su nacimiento y la cotidianidad de sus días.

El promotor de lectura de la Fundación siempre asume una actitud de respeto sobre lo que se dice y quién lo dice, dando así importancia al narrador y a su historia, busca poner en común situaciones de crianza de cada familia, compartir concepciones, dudas, hacer de éste un espacio que responda a los intereses de las familias:

a)-Cuando nací, mi mamá cumplía 8 meses de tener en su vientre la personita que la va a acompañar por toda su vida. Tenía mucho afán de conocer a mamá y a papá que ustedes comprenderán tenia afán, estaba tan apurado de llegar a mi nuevo hogar aunque en el que me encontraba era muy rico y caluroso. Pasó mi primer mes pegado al seno, que es lo más rico que he probado en la vida (Diario, participante 10).

b)-No me dejaba dormir de noche pero fue creciendo y fue durmiendo mejor, no le gusto el alimento materno, le gustaba era el tetero y el papá era muy feliz porque era su primer hija 
él no consentía ni que se le parara una mosca y hasta el día de hoy (Diario, participante 4 ).

Este proceso les reconoce a los niños y a las niñas un lugar en la historia familiar, convierte su vida en palabras, narración y en personajes que provocan una historia. Por voluntad propia, estos diarios se comparten con los compañeros del taller, se hacen públicos y se convierten en motivo de conversación.

Aprender a usar el lenguaje comprende el aprendizaje de la cultura y el aprendizaje de cómo expresar las intenciones de acuerdo con ella. Esto nos lleva a formular la pregunta de ¿cómo podemos concebir la cultura y de qué modo ésta brinda los medios no solo para realizar transacciones con los demás sino para concebirnos a nosotros mismos en esas transacciones? (BRUNER, 2004, p. 75).

En torno a la lectura de los diarios aparece la conversación, se da la palabra a cada adulto para expresar sus concepciones del mundo y de la crianza en particular, hacer pública la historia de vida, ceder a cada participante la voz para que saque de su alma acontecimientos y sentimientos que la mayoría de las veces no ha tenido la oportunidad de expresar. Convergen la expresión y la escucha como posibilidades de contacto.

Él se me declaro y yo me quede atónita callada, yo era temblando, esperando a ver qué me iba a salir y nada le colgué... Empezamos ya a planear lo de la niña... cuando yo me di cuenta fue muy emocionante... le empezaba a colocar música muy suave, instrumental, le ponía colores, papeles de colores... a los tres meses... los vómitos le dieron a él, los vómitos los mareos... a él le toco todo, los vómitos, los antojos de todo se antojaba (Diario, participante 2 ).

Con la escritura de los diarios del bebé se logra que cada uno sea protagonista, un provocador de una historia, un ser con la capacidad para cambiar el devenir de unas vidas que parecen marcadas por el contexto. Esa narración se convierte en motivo de reflexión sobre el pasado y las posibilidades de futuro. A través de él, las familias tienen la posibilidad de imaginarse un futuro y lo que requieren para que sea posible:

Me enseñaron que lo que uno le enseñaba al niño desde el vientre era lo que iba ser el niño... me di cuenta que lo que usted hacía cuando estaba en embarazo era lo que le iba a fomentar al bebé cuando él naciera, entonces yo empecé todas las noches la rutina de leer, le contaba historias, me tocaba la barriga, le contaba la historia del papá y la mamá (Participante 1). 


\subsection{Del ser madre}

El grupo de asistentes está compuesto por unas trece familias, de las cuales ocho asisten regularmente y todas son mamás, mujeres que en términos generales dedican todo su tiempo a cuidar de sus hijos y a realizar las labores domésticas. Cinco de ellas no tienen un empleo externo porque sus compañeros no se los permiten o porque no lo conciben; dos reparten su tiempo entre la universidad y su familia, y una trabaja medio tiempo en una panadería.

Ellas llegan al taller en la búsqueda de mejorar sus prácticas de crianza y de ofrecerles algo a sus hijos, pero a través de ellos entienden su propio goce y posibilidad de expresión. El taller es un espiral en el que la expresividad se abre en los bebés, pero ellas tienen la oportunidad de encontrarse con el lenguaje, conocer la fantasía, la literatura, la escritura, y por esta vía pensarse como protagonistas de una historia. En el taller cada uno tiene la oportunidad para gestar alternativas que les permitan conocer a sí mismo y construir ambientes para el encuentro con los otros.

El periodo de realización de esta investigación coincidió con la celebración del Día de la Madre en Colombia, situación que permitió un acuerdo entre el promotor de lectura y las investigadoras para hacer una sesión en la que se hiciera un homenaje a las mamás con música, poesía y conversación. Dicha sesión se menciona en este documento como el "Taller Tematizado". En este momento las mamás manifestaron que era para ellas ser madres: "Es como un arcoiris" (Participante 6); "Es lo que le da el verdadero sentido a mi vida" (Participante 8); "Es la prolongación de uno sobre la tierra" (Participante 11).

Para todas las participantes, la maternidad es el destino y la realización femenina, y además la procreación es constitutiva de las parejas: "A un matrimonio sin niños le queda faltando algo" (Participante 6). Quizás por ello no se planea, este nuevo ser llega en momentos inesperados, pero siempre se recibe con alegría o resignación:

-Fue una felicidad muy grande para todos... también me dio mucho susto, yo tenía otros planes... para el papá también fue muy sorpresivo (Participante 1 ).

-Cuando quedé embarazada todavía no queríamos, al darnos cuenta nos pusimos muy contentos (Participante 3 ).

-Donde comen cinco, comen seis, él tiene un techo donde llegar (Participante 5).

Además las concepciones religiosas reafirman el rol materno: "Yo tengo seis hijos y no me opero, porque él dice que como nosotros somos casados por la iglesia, Dios mandó la mujer para tener hijos" (Participante 4). 


\section{Algunas conclusiones}

En este apartado se pretende dar cuenta de las principales conclusiones que arroja el trabajo de investigación en los siguientes aspectos:

Desde el fortalecimiento del vínculo afectivo entre madres/padres o cuidadores/as y los niños y las niñas:

a)El Taller llega en un momento temprano y oportuno del desarrollo de los niños y niñas, lo que posibilita que la construcción del lenguaje se dé en un espacio común con sus adultos significativos, les crea una conexión social en los ámbitos físico, intelectual y emocional como punto de partida para su crecimiento.

b)Desde que el niño nace lee el mundo, comienza por leer los rostros y todos los objetos que hacen parte de ese mundo que habita. Este primer momento de lectura le permite al niño o la niña comenzar a comprender el mundo, se convierte en una de las primeras acciones del recién llegado para acomodarse a su nueva vida.

En suma, el fortalecimiento del vínculo afectivo entre madres/padres o cuidadores/as y los niños y las niñas se ve reflejado en asuntos tales como

a)El reconocimiento del lugar que el niño y la niña ocupan en el mundo, en sus hogares y en la comunidad.

b)El reconocimiento de la voz del niño y la niña, así como de sus expresiones y requerimientos de afecto, cuidado y atención.

c)La generación de ambientes de seguridad emocional $y$ afectiva para sentir confianza en sí mismos y en los otros.

d)La superación del dolor, del olvido y del maltrato por la negación, por la ausencia o la invisibilización a la que son sometidos los niños y las niñas. Se trata de pronunciar la palabra que cura y la caricia que alivia.

e)El fortalecimiento de las potencialidades de los niños y de las niñas, su resonancia en el contexto y la estima que reciben de los otros.

F)El reconocimiento de la singularidad de los niños y de las niñas. Reconocer su propio modo de ser, su búsqueda de ser siempre de un modo siempre distinto y auténtico.

Desde la comprensión del lugar de la biblioteca pública como ambiente potenciador del afecto: 
a)Con el programa PARAMÁ PARAPÁ, la Fundación Ratón de Biblioteca transciende el quehacer de la biblioteca pública como promotora de lectura, y más bien la transforma en una institución social que participa en el fortalecimiento de vínculos afectivos entre los niños y niñas y sus familias, además contribuye a la formación de prácticas de crianza favorecedoras para el crecimiento de los niños y las niñas desde los primeros años de vida.

b)La capacidad de la Fundación Ratón de Biblioteca para utilizar las herramientas de promoción de lectura para escuchar y ayudar a verbalizar las inquietudes de adultos significativos interesados en mejorar como sujetos de crianza, se constituye en un enfoque valioso para las entidades y personas interesadas en convocar en torno a iniciativas de fortalecimiento familiar, crecimiento y desarrollo de la infancia - mejoramiento de prácticas de crianza y lograr así, la participación permanente e interesada de las familias.

Desde la comprensión de la lectura como práctica vinculante que favorece el cuidado de sí y del otro:

a)Con las sesiones de lectura, acompañada de música, literatura, conversación y manualidades, los adultos pasan de una disposición mental y corporal hacia los niños y niñas, a un escenario enriquecido en lenguajes para expresar su amor y su capacidad de acompañarse. Les permite a los adultos salir de la rutina, de las actividades propias de la cotidianidad como la alimentación, el baño y los cuidados básicos, para llegar a un lugar en el cual experimentan la sensación de placer y bienestar para encontrarse con sus hijos, consigo mismos y con sus pares.

b)Especialmente para las mujeres es un espacio que les permite encontrarse con la palabra, la lectura y la escritura, tener un espacio para sí, y verse a sí mismas a través de la historia de sus hijos. Las estrategias de promoción de lectura les entregan su voz y les dan un turno para encontrar su propio lugar en la historia.

En suma, es posible afirmar que el lenguaje tiene directa relación con el afecto y con el tacto. Sin el lenguaje no puede ser posible el afecto (el afecto recurre al lenguaje y a las palabras para materializarse), pero sin el afecto tampoco es posible sin el lenguaje (sin el sentirse implicado con el otro, las palabras serán reflejos vacíos y fríos), sin atender a la expresión o la demanda de atención del otro, de aquel que reclama y espera. 


\section{Referencias}

ÁLVAREZ ZAPATA, D. Del modo de leer como modo de producción y consumo textual: ideas fundamentales de una categoría en contrucción. Revista Educación y Pedagogía, v. 14, n. 32, p. 137-149, 2002.

ÁLVAREZ ZAPATA, D. De leer, un viaje por la promoción de la lectura: guía metodológica. Medellín: Universidad de Antioquia. Escuela Interamericana de Bibliotecología, 2008.

ÁlVAREZ ZAPATA, D. \& NARANJO VÉLEZ, E. La animación a la lectura: manual de acción y reflexión. Medellín: Universidad de Antioquia. Escuela Interamericana de Bibliotecología, 2003.

BÁRCENA, F. El delirio de las palabras: ensayo para una poética del comienzo.Barcelona: Herder, 2004.

BERGER, P.; LUCKMANN, P. La construcción social de la realidad. Buenos Aires: Amorrortu, 2003.

BRUNER, J. Realidad mental y mundos posibles: Los actos de la imaginación que dan sentido a la experiencia. Barcelona: Gedisa, 2004.

FUNDACIÓN ÉXITO. Informe de gestión 09. Medellín, 2009.

FUNDACIÓN RATÓN DE BIBLIOTECA. Proyecto educativo institucional. Medellín, 2009

GENOLET, A. et al. Trayectorias de vida y prácticas maternales en contextos de pobreza. Ciencia, docencia y tecnología, v. 20, n. 38, p. 13$35,2009$.

HECKMAN, J. Inversión social en capital humano y pobreza. In: CONFERENCIA EN LA INAUGURACIÓN DEL CENTRO DE EVALUACIÓN Y ESTUDIOS EN ECONOMÍA SOCIAL PARA EL ALIVIO DE LA POBREZA. Argentina: Universidad Torcuatto di Tella, Octubre 2001

JARAMILLO, O. et al. La biblioteca pública: una mirada desde su génesis y desarrollo. Medellín: Universidad de Antioquia; Escuela Interamericana de Bibliotecología, 2005.

MORENO, L. A. La educación temprana de los niños: una revolución educativa para América Latina. El Tiempo, p. 1-24. 30 ago. 2009.

MUSTARD, J. F. Desarrollo infantil inicial: salud, aprendizaje y comportamiento a lo largo de la vida. En Primera infancia y desarrollo. El desafío de la década. p. 85. Bogotá: Centro Internacional de Educación y Desarrollo, CINDE, 2003.

OATES, J. La primera infancia en perspectiva 1: relaciones de apego, la calidad del cuidado en los primeros años. Reino Unido: Editores de la serie: Martin Woodhead, 2007.

REYES, Y. Lectura en la primera infancia: cuando leer es mucho más que hacer tareas. Nuevas Hojas de Lectura, v. 3, p. 20-29, 2003. 
RICOEUR, P. Volverse capaz, ser reconocido [versión electrónica]. Espirit, v. 7, p. 125-129, 2005.

SUÁREZ SERRANO, I. El lugar de la maternidad en la construcción de la feminidad: un estudio cualitativo de cuatro casos de mujeres adolescentes. Revista Adolescencia y Salud , 21-35, 1999.

UNESCO. Manifiesto de la IFLA/Unesco sobre la biblioteca pública. Disponible en: <www.archive.ifla.org/VII/s8/unesco/span.htm1994>. Acceso en: 21 octubre 2009. 